\title{
TOPONIME ÎN BASME ROMÂNEȘTI - ÎNTRE SACRU ȘI PROFAN
}

\author{
Veronica ONET \\ Universitatea Tehnică din Cluj-Napoca, \\ Centrul Universitar Nord Baia Mare, România
}

Toponyms in Romanian fairy tales - between sacred and profane

\begin{abstract}
This paper aims to approach names of places in literary texts, particularly in fairy tales. Starting from the premise that the fairy tale fictional world is structured on the principle of duality - good vs. evil -, we will show that names of places in fabulous discourse can also be classified as good or bad. However, there is no clear delimitation between the two toponymic categories: at some point, some names change their meaning from good to evil and vice versa.

Thus, we will investigate the lexico-semantic status of toponyms in the fabulous universe diachronically by looking at classical and modern fairy tales. At the same time, we will underline the similarities and structural and content differences between Romanian toponyms (the formation of toponyms predominant in the type of text investigated).

The approach is interdisciplinary, the areas concerned being anthropology, ethnolinguistics and semantics.

The corpus is taken from Romanian fairy tale anthologies and cartoon/children's films.
\end{abstract}

Keywords: literary onomastics, fairy tale, appellative, toponyms, archetype.

\section{Forme elementare ale sacrului vs. profanului manifestate în toponimia din basme}

Numele de locuri din basme sunt reflecții ale perioadei precreștine, reminiscențe ale totemismului și animismului - forme elementare de manifestare a religiosului. Ideea de bine și rău, benefic vs. malefic a fost ulterior împărtășită de creștinism și preluată prin înlocuirea termenilor menționați mai sus cu sacru și profan. Astfel, prin conotație, $z m e u l$ a devenit drac, iar împărăția acestuia, iad. Tot astfel, alături de caracterul social ${ }^{1}$ și istoric, toponimele poartă amprenta unor credințe și superstiții impregnate în

1 Multe toponime au fost expuse în timp modificărilor pe cale administrativă („In Romania, Brașov became Orașul Stalin (Stalin city) in 1950-1960. The return to the previous name was favored by the death of the dictator (in 1953), Khrushchev's rise to power (in 1956), and the retreat of the Sovietic troops from Romania (in 1958). Other notable examples are Eforie Sud > Vasile Roaită (1949-1965); Ștei > Orașul Dr. Petru Groza, adopted until 1996, after the former president of the Council of Ministers died in 1958; and Onești > Gheorghe Gheorghiu-Dej, since the death of the communist leader in March 1965 until 1996") (Felecan, O. 2017: 80). 
subconștientul colectiv. Locuri precum apele stătătoare, cerul, marea, pădurea, pământul (nume apelative întâlnite în glosarul toponimic și în basme), în sens extins, și fântâna, grădina, izvorul, prăpastia, stânca, în sens restrâns, reprezintă arhetipuri materne cu rol ocrotitor (vezi Jung 2003: 92). Altfel spus, omul și-a împărțit universul în locuri curate, reprezentate de spațiul umanizat și în locuri necurate, care trezesc spaime și temeri legate de necunoscut. Omul arhaic, fie le evita, fie încerca să le domine prin săvârșirea unor rituri apotropaice și propițiatice. Eliade (2000: 17) consideră că „locurile sacre nu sunt omogene, ci prezintă rupturi și spărturi și sunt singurele care există cu adevărat”. Plecând de la ideea că „inconștientul posedă orizonturi proprii”, Lucian Blaga (1985: 196) este de părere că în cultura românească există „o viziune spațială specifică, care ia forma determinată a «infinitului ondulat»”, iar acest cadru este numit „spațiul mioritic". Glosarul toponimic cuprinde nume formate de la termeni religioși, hagiotoponime (Chilia, Dealul Crucii, Poiana Crucii sau prezente în basme Iadul, Raiul), care semnifică credința ființei umane că „omul sfințește locul”. În acord cu Daiana Felecan (2017: 19-34), numele din basme aparțin, fie unui „sacru constitutiv” (Rai), fie sunt susceptibile sacre (Împărăţia Zorilor). Altfel spus, cele mai multe toponime „suferă” de o „sacralizare prin metaforizare” (Ibidem 2017: 19-34). Numele de locuri sunt fapte de limbă create prin voința colocutorilor, conform normelor lingvistice și au rol de identificare locală, servind la derularea actului de comunicare între indivizii unei comunităţi. „Place names are not only linquistic signs $[\ldots]$ they also represent social and historical values" (David 2011: 215) și, am adăuga noi, valoare emoțională, care reflectă, atât relațiile interumane, cât și legătura omului cu spațiul geografic.

\section{Statutul toponimelor în basme}

Tiparul denominativ al basmului, cu referire la numele de locuri, este relativ omogen, fiind constituit din apelative in funcție toponimică. Multe dintre acestea sunt termeni entopici care pot fi grupați în câmpuri toponimice ${ }^{2}$, bazate, fie pe diferențiere, fie pe polarizare 3 . În acord cu Moldovanu (2010: 18), admitem că un câmp toponimic este diferit de cel lexical, deoarece primul amintit se referă la valoarea numelor, la importanța sociogeografică realizată de nominatori. Astfel, câmpul toponimic polarizator se bazează pe o „diferențiere a valorii numelor în condițiile contiguității obiectelor geografice corespunzătoare", și nu pe opoziții lexicale. În schimb, câmpul toponimic diferențiator se compune pe baza acestor opoziții lexicale, echipolente, graduale, privative $e^{4}$, fiindcă diferențierea opune lexeme corespunzătoare din același câmp lexematic ierarhizat.

2 Câmpul toponimic este „un ansamblu denominativ, dezvoltat în jurul unui toponim de bază, cu rol de centru polarizator în seria toponimelor polarizante” (Moldovanu 2010: 229).

3 „Polarizarea este procesul de creare a unor derivate toponimice de la un toponimnucleu, corespunzând obiectului cel mai important dintr-o mapă geografică continuă (unitară) [...], diferențierea toponimică este procesul prin care se desemnează, cu ajutorul unor delimitatori lexicali, părțile unui obiect geografic denumit” (Moldovanu 2010: 18-19).

4 Conceptul de opoziție a fost dezvoltat de Coșeriu (2016: 99), care 1-a preluat din 
Așa cum universul nostru este structurat bipolar, sacru vs. profan, și toponimele din basme pot fi divizate în bune și rele. Dar, specificăm că, în acord cu Eliade (2000: 19), sacrul este camuflat în profan, că nu există o limită clară între cele două noțiuni, deoarece unele spații profane, într-un anumit interval de timp, pot fi sacralizate prin rituri propițiatice. Muntele, Pădurea sunt apelative cu rol denominator și devin spații benefice prin trecerea pragului liminal (Hotarul sau Răscrucea) și prin săvârșirea unor rituri de trecere ${ }^{5}$, deoarece în trecut niciun act nu era absolut independent de sacru (basmul păstrează și la nivel nominal formele de existență primară). Astfel, putem structura toponimele, pornind de la tipul locului în sine, deoarece legătura nume - spațiu este în basme una directă și indestructibilă.

Dacă, în realitate, apelativele devenite toponime, de cele mai multe ori, sunt opace, pierzându-și legătura cu etimonul său, prin polarizare, pot denumi și alte locuri geografice decât cele care sunt reperate prin termenul generic, în basme toponimele sunt pure, primare, păstrând legătura cu apelativul. Acestea din urmă sunt transparente și motivate contextual, „motivation through connotation, including biblical, historical allusions, evoation of a personality, of a social or cultural context, everything that is situated in the sphere of intertextuality an dis associated with a name or is suggested by a surname or first name" (Munteanu 2016: 63) ${ }^{6}$.

Atât locurile în universul fabulos, cât și numele lor se situează între două repere spațiale, considerate puncte limită ale verticalei și axei noastre, Fundul Pământului / Capătul Pământului și Înaltul Cerului. Între acești poli opuși întâlnim variate locuri, fie bune, fie rele, cu nume generice.

\section{Palierul lexico-semantic}

Grupând numele în câmpuri toponimice putem identifica următoarele categorii:

Câmpul toponimic diferențiator bazat pe opoziții privative ale arhilexemului „pământ”: Buricul Pământului ${ }^{8}$ (nume metonimic conotat ca prag liminal de trecere spre Celălalt Tărâm și există analogia cu buricul omului, considerat centru, mijloc), Marginea Pământului. În cadrul acestui câmp distingem seria sinonimică Buricul

fonologie (Trubetzkoy) și l-a extins la domeniul lexical. Lingvistul identifică opoziții graduale constituite prin „gradația unei anumite calități, un exemplu dat fiind cel al gradației evaluării elevilor”, opoziții echipolente constituite „din termeni echivalenți din punct de vedere logic, prin raportare la conținutul comun, exemplificat prin câmpul culorii cromatice: roșu - portocaliu galben - verde", opoziții privative sunt redate prin contrastul albus/candidus, niger/ater.

Vezi în acest sens Arnold Van Gennep (1998: 17).

6 [„Motivare prin conotație, fiind incluse aici numele biblice, cu aluzii istorice, cele care evocă personalități din arealul social sau cultural, tot ce este situat în sfera intertextualităţii și poate fi asociat cu numele sau poate sugera numele de familie sau prenumele"].

7 Arhilexemul este „o unitate ce corespunde întregului conținut al unui câmp lexical” (Coșeriu 2016: 96).

8 „Buricul Pământului e un fel de deschizătură care se afla în mijlocul pământului și prin care trec vitejii din povești pe celălat tărâm” (Fochi 1976: 82). Sau ar fi „o gaură prin care intră și ies dracii din Iad. E ca o fântână părăsită și greu mirositoare” (Pamfile 2002: 234). 
Pământului / Miezul Pământului / Mijlocul Pământului și Marginea Pământului / Capul Pământului / Coada Pământului, folosite cu aceeași semnificație. Lexemul „tărâm” intră în componența unor nume care pot fi incluse într-un câmp diferențiator, prin opoziții privative (Tărâmul de Sus vs. Tărâmul de Jos) ${ }^{9}$;

Câmpul toponimic al arhilexemului „unitate teritorială”: Împărăție < împărat + -ie (Împărăția Doamnei Chira Chiralina, Împărăţia Sorilor, Împărăția Zorilor); Meleag < ung. mellék „regiune învecinată, cuprins al unei așezări omenești” (DLR 2010: s.v.) (Meleaguri Pustii - epitet bazat pe raportul antonimic așezare omenească și pustietate); Moșie < moș + -ie (Moșia Gheonoaiei, Moșia Împăratului Verde, Moșia Scorpiei). În acest palier semantic polarizarea este sociogeografică (Moldovanu 2010: 19), deoarece punctul de origine îl constituie proprietatea unei anumite persoane. În acest caz, cuvântul care denumește domeniul lipsește, dezvoltarea toponimică realizându-se direct de la numele proprietarului (Împărăția Sorilor, Împărăția Șoarecilor, Împărăția Căpcăunilor, Moșia Gheonoaiei, Moșia Scorpiei). Astfel, la baza structurii topicului nu stă ideea de proximitate geografică, ci numele de persoană / ființă mitologică care este polarizatorul. Antroponimele Căpcăun, Gheonoaie, Scorpie fac parte din categoria numelor malefice și prin contagiune se realizează transferul profanului și asupra numelui de loc pe care îl posedă. Multe porecle devin etichete emblematice ale purtătorilor și, prin transfer metonimic, ele ajung să denumească o comună, un munte, un sat etc. „Nicknames have become means of attack, picked by belligerent interlocutors form the arsenal at hand. They are prolonged - relase antidotes used to destroy opponents and their effect is visible in the long run, as nicknames become part of users' colective memory" (Felecan, D., O. Felecan 2016: 191);

Câmpul toponimic al arhilexemului „antropic”: includem spațiul familiar, umanizat, cu proprietăți sacre. Bordei - origine necunoscută, „locuință rudimentară pe jumătate săpată în pământ și acoperită cu paie, pământ, stuf” (DLR 2010: s.v.); Casă < lat. casa, -ae (Casa de Alamă, Casa de Argint, Casa de Marmură, Casa Zmeoaicei Pământului, Casa Legată de Toartele Cerului); Castel < lat. castellum „construcție mare, fortificată, care servea ca locuință seniorilor” (DLR 2010: s.v.) (Castelul de Aramă, Castelul de Argint, Castelul Împăratului Verde, Castelul Zmeului); Palat < lat. palatium „clădire monumentală care servește ca reședință unui suveran” (DLR 2010: s.v.) (Palatul de Aramă, Palatul de Argint, Palatul de Cleștar); Serai < turc. seray, saray „palat al sultanului sau al marilor demnitari turci” (Șăineanu 1997: 119) (Serai de Sticlă). Numele topice din acest câmp denotă, fie posesia (Casa Zmeoaicei Pământului, Casa Zmeului, Castelul Împăratului Verde), fie materie (Casa de Alamă, Castelul de Aramă, Palatul de Cleștar, Serai de Sticlă). De asemenea, aceste toponime sugerează statutul social al proprietarilor. Spațiul exterior casei este reprezentat de Curte (Curtea Împăratului Roșu) / Bătătură (Bătătura Împăratului); Hotar (Hotarele Scorpiei, Hotarele Zmeilor), Pod (Pod

9 „În viziunea spațială a lumii la poporul român, «celălalt tărâm» nu are determinare precisă de loc; uneori e sub pământ, alteori în pământ și nu sunt rare cazurile când este imaginat undeva în spațiul atmosferic, către cer" (Bernea 1997: 92). 
de Aramă, Pod de Argint, Pod de Aur), Răscruce - „loc unde se încrucișează sau de unde se separă două sau mai multe drumuri” (DLR 2010: s.v.) - forme de trecere din lumea cunoscută, familiară, sacră, într-o lume necunoscută, străină, profană.

Câmpul toponimic al formelor de relief cu conotație pozitivă (formele de relief sunt clasificate de geografi în raport cu un plan orizontal, în pozitive - deal, movilă, munte și negative - depresiune, râpă, vale) (vezi Ielenicz 2004: 7): Câmp < lat. campus „,̂ntindere de pământ (arabil) fără accidente importante” (DLR 2010: s.v.) (Câmp cu Iarbă Verde, Câmp Frumos). În interiorul acestei categorii întâlnim un câmp diferențiator format din numele Câmp și derivatul Câmpuleț < câmp + -eț; Codru < lat. quodrum (quadrum) „pădure mare, deasă, bătrână” (Codru Verde). În opoziție se află topicele (Codru Verde / Vârfu Codrului). Deal < sl. delŭ „ridicătură a scoarței pământului mai mică decât muntele" (Șăineanu 1997: 217) (Dealul de Marmură, Dealul La Spânzurătoare - cu conotații negative); Grădină < bulg., sb. gradina „teren (îngrădit) pe care se cultivă flori, legume sau pomi fructiferi” (Șăineanu 1997: 345) (Grădina Împăratului, Grădina lu Ileana Cosânzeana, Grădina Ursului - posesie); Hățiş (orig. nec.) „grup de tufe de mărăcini, desiş într-o pădure” (Şăineanu 1997: 357); Izlaz< bulg. Izlaz „loc pentru păşunat, imaș” (Șăineanu 1997: 406). În basmele cercetate de noi, am găsit două nume care au în componența lor topicul menționat anterior, Marginea Izlazului și Pe Fundu Izlazului aflate în opoziție. Munte < lat. mons, -ntis „,ridicătură a scoarței pământului, cu înălțimi care depășesc o anumită altitudine” (DLR 2010: s.v.). Numele care denumesc oronime, identificate în basmele analizate de noi, sunt grupate din punct de vedere semantic astfel: cele care arată însușiri (Munții Cocâlcâi, Munții Crunții - probabil aici au avut loc războaie sângeroase, deoarece termenul „crunt” < lat. cruentus are sens învechit „plin de sânge, muiat în sânge” (DLR 2010: s.v.), Munții Înalţi), o stare climatică (Munții Secetei), materie (Munții de Iagă < ung. uiágă „,sticlă”, Munții de Piatră și Nisip, Munții de Sticlă), evenimente istorice (Munții Galionului au probabil forma unei corăbii, amintind de nave cu pânze, de mari dimensiuni, cu mai multe punți, utilizate în trecut); Pădure < lat. paludem „întindere mare de teren, acoperită cu arbori" (Șăineanu 1997: 620), intră în categoria formelor de relief cu conotație pozitivă. Numele din acest segment sunt divizate după cum urmează: cele care sugerează termeni cromatici (Pădurea Neagră - densitate, necunoscut, spațiu profan prin adăugarea adjectivului „negru”, Pădurea Roșie - calificativul „roșu” denotă sângele și afectivitatea, relația care există între spirit și corp), stare climatică (Pădurea cu Căldură, Pădurea cu Ger - opoziție), însușiri (Pădurea Râioasei), termeni din sfera magicului (Pădurea Blestemată), faună (Pădurea Ursului), materie (Pădurea de Aramă, Pădurea de Aur, Pădurea de Fier). Întâlnim și derivatul Pădurice (pădure + -ice), precum și Mijlocul Pădurii, în opoziție graduală cu Marginea Pădurii. Poiană < sl. poljana „loc cu iarbă și flori, fără copaci, în interiorul unei păduri” (Șăineanu 1997: 668). În opoziție se află Poieniță (poiană +-iță) și Poiană Mare.

Câmpul toponimic al formelor de relief cu conotație negativă - arhilexemul „apă stătătoare”: Balta < sl. blato, $c f$. alb. baltë „,apă stătătoare permanentă, cu faună și vegetație specifică” (DLR 2010: s.v.) (însușire - Balta Stuhoasă). În opoziție, formând 
un câmp diferențiator se află topicul Balta și Băltoaca (derivare augmentativă baltă + -oacă). Eleșteu < ung. halastó „iaz cu pește”, Fântână < lat. fontana „groapă săpată până la nivelul unui strat de apă și amenajată pentru alimentarea curentă de apă” (DLR 2010: s.v.), (Fântână Otrăvită - însușire, Fântâna Sânzâienelor - posesie). Este prezentă și opoziția Fântână - Fântâniţă și Fântână - Fundul Fântânii. Halău < magh. háló „troaca aia între două dealuri, ca un părău”, ,jgheab natural, depresiune alungită și mai strâmtă, adâncitură de teren în forma unui halău”, ,jgheab pentru adăpat vitele” (Loșonţi 2000: 160); Iaz < sl. jazŭ „lac artificial format prin stăvilirea sau abaterea unui curs de apă” (Iazul Morii); Iezerul < sl. jezerŭ „lac adânc, loc mocirlos” (Șăineanu 1997: 376); Lac < lat. lacus „mare întindere de apă stătătoare, înconjurată de uscat” (DLR 2010: s.v.) (Lacul cu Lapte Dulce). Am întâlnit și forme regionale Lacul cu Lapți Dulce sau Tăul cu Lapte Dulce; Mlaștina < sl. mlaština „depresiune naturală în care se adună apa provenită din precipitații sau din pânza freatică și pe al cărei fund se formează nămol” (DLR 2010: s.v.); Smârc < sl. smrǔkŭ „în basme: loc îndepărtat și primejdios, de unde își trage marea izvoarele" (Şăineanu 1997: 150).

Câmpul toponimic al formelor de relief cu conotație negativă - arhilexemul „apă curgătoare”: Gârlă < bulg. gărlo „apă curgătoare mică, ramificație, braț al unei ape” (Șăineanu 1997: 339); Hoagă „e ca o obârșie de pârâu, groapă cu apă, vâlcea, văgăună afundată, viroagă, lăsătoare” (Loșonți 2000: 163-164); Valea < lat. vallis „depresiune, adâncitură de teren alungită, străbătută de o altă apă curgătoare; pop. apă curgătoare, albia unei ape curgătoare" (DLR 2010: s.v.) (Valea Adâncă, Valea Plângerii). Valea se află în opoziție cu Vâlcea.

Câmpul toponimic al formelor de relief cu conotație negativă - arhilexemul „teren situat în apropierea unei ape”: Luncă < sl. lonka „baltă”, „câmpie acoperită cu fânețe în apropierea unui râu sau la poalele unui deal ori al unui munte" (DLR 2008: s.v.), Ostrov < sl. ostrovŭ „,insulă mică, adesea plutitoare, formată într-o apă curgătoare, acoperită, de obicei, cu vegetație” (DLR 2010: s.v.) (Ostrovu Florilor - floră, Ostrovu Mării și al Oceanelor - acvatic); Preluca < sb. preluka, ucr. priluka „(reg.) poiană mică între munți sau între dealuri (pe valea unei ape)" (Șăineanu 1997: 692); Râpa < lat. ripa „surpătură de pământ făcută de șuvoaie” (Șăineanu 1997: 56) (Râpa Arapului).

Glosarul toponimic al basmelor analizate este format, în mare parte, din apelative în funcție toponimică, acest lucru facilitând decodarea cu ușurință a denominațiilor propriale. Cele mai multe dintre acestea aparțin vocabularului fundamental, dar am întâlnit și apelative care fac parte din masa vocabularului (regionalismele Halău, Hoagă, Munții Cocâlcâi, Tăul cu Lapte Dulce). În basme este păstrată cu strictețe gândirea arhaică, care prevede existența unei legături magice între nume şi loc, numită în literatura de specialitate iluzie referențială (bazată pe principiul nomen est omen) (v. Nicolaisen 2011: 137-145). 


\section{Palierul etimologic}

Dacă în cadrul toponimelor reale, pentru a identifica etimologia unui nume ${ }^{10}$, trebuie să avem în vedere „cronologia unor fenomene lingvistice și istorice” (Toma 2015: 75), etimonul toponimelor imaginare este mai uşor de găsit, datorită apelativelor care intră în structura numelor. Acestea păstrează transparența și motivația dintre nume și locul denumit în basme.

Toponimele din universul fabulos, cercetate de noi, sunt în totalitate românești, dar apelativele din care provin au etimon bulgar, maghiar, slav, turc, ucrainean etc. Astfel, identificăm din substrat: (Balta, Măgura, Pârâu); latine (Bătătura, Casa Zmeoaicei Pământului, Castel de Aramă, Câmp Frumos, Codru Verde, Curtea, Fântâna Sânzâienelor, Împărăția Sorilor, Lacul cu Lapte Dulce, Munții Crunții, Pădurea Roșie, Râpa Arapului, Valea Plângerii); slave (Baltă, Crâng, Dealul de Marmură, Iaz, Iezer, Mlaștină, Ostrovul Florilor, Podul de Aur, Poiana Mare, Smârcurile Mării); împrumuturi: bulgare (Gârlă, Grădina Împăratului, Izlaz, Livadă, Pogon), maghiare (Eleșteu, Halău, Hotar, Meleaguri), sârbești/ucrainene (Preluca), turcești (Hanul, Serai de Sticlă); formații interne (Moșia); origine incertă (Bordei, Hățiş). După cum se observă, cele mai multe apelative provin din latină, maghiară și slavă.

\section{Palierul onomastic}

Glosarul toponimelor din basme cuprinde nume de locuri fictive, care nu au un referent în spațiul real, și topice, care există în realitate. Considerăm că locurile ficționale au în discurs același statut pe care îl au ființele/ locurile despre care noi știm sau credem că există. „Ces noms ont un référent: qu'il soit fictif ou réel n’a aucune incidence sur son fonctionnement linguistique" (Vaxelaire 2005: 141).

Astfel, în acord cu Ainiala et al. (2016: 257), topicele din basmele cercetate de noi se pot clasifica în: nume reale - cu un referent în realitate (hidronime - Dunărea, Marea Neagră, Argeș, Apa Iordanului, oronime - Munții Pădurea Neagră), nume fictive (unele nume posibil să fi existat/ să existe în realitate, dar altele sunt cert fictive) $\mathrm{cu} /$ fără un referent în lumea reală (hodonime - Calea Cătușii, oiconime - Baltonești, Batistești, Biciuiești, Casa Zmeoaicei Pământului, Celălalt Tărâm ${ }^{11}$, Comuna Cătească, Pălmești, Pumnești, Scărești), hidronime - Bătătura Împăratului, Castelul lui Crăcănea, Dealul de Marmură, Fântâna Sânzâienelor, Grădina Ursului, Hotarele Zmeilor, Lacul cu Lapte Dulce, Munții de Iagă, Ostrovu Mărilor, Pădurea Râioasei, Smârcurile Mării etc.). În basme predomină numele fictive, deoarece „unitatea de măsură a «lumii ficționale»

10 „Cel mai bun mijloc ca să ne asigurăm că etimologia numelui topic este justă e să cunoaștem povestea care a dus la crearea lui. Trebuie să fim totuși atenți la faptul că povestea poate fi fabricată special pentru a servi ca bază unei etimologii, de obicei fanteziste" (Graur: 1972: 21).

11 „Trebuie făcută o distincție clară între Cealaltă lume a basmelor, văzută ca un univers paralel, sub pământ, deasupra acestuia sau la capătul lui, în care locuiesc atât ființe umane, cât și nonumane, caracterizată de numeroase deosebiri ce îi subliniază caracterul aparte, bogăţia” (Olteanu 2009: 6). 
nu este aderența la o realitate verificabilă senzorial, ci pertinența la o «lume posibilă», creată de producător și validată de consumator" (Felecan, D. 2015: 56).

Din punct de vedere formal, toponimele din basme pot fi clasificate în: simple - alcătuite dintr-un singur cuvânt, monomembre (Gârla, Izlazul, Mlaştina), derivate cu afixe (augmentative - Băltoacă, diminutivale - Fântâniţa, Păduricea, Poieniţa, plurative - -ești Baltonești, Batiștești, Pălmești, Pumnești, Scărești), compuse (majoritatea toponimelor în basmele cercetate de noi sunt compuse - Buricu Pământului, Fundu Pământului, Hotarele Zmeilor, Tărâmu Celălalt). Am identificat în basmele alese câteva nume care au în componența lor termeni religioși (hagiotoponime - Apa Iordanului, Iadul, Pădurea Blestemată, Raiul, Răscrucea, Tărâmul Drăcesc). Unele toponime au în structura lor un antroponim (Împărăția Doamnei Chira Chiralina, Castelul lu' Crăcănea, Grădina lu' Ileana Cosânzeana). Toponimele se pot clasifica în funcție de structura lor, în toponime primare, acestea fiind alcătuite numai dintr-un termen generic, care prin onimizare devine toponim și toponime secundare, alcătuite dintr-un termen generic și din determinante multiple.

Numele care au terminații în -a, -ele/ile (Curtea Împăratului Roșu, Grădinile Împăratului, Hotarele Scorpiei), doar în aparenţă sunt articulate, aceste terminații au rol deictic și de marcare a formei de singular/plural, fiind moștenite de la apelative. De asemenea, există în basme tipare denominative specifice sub forma unor propoziții cu rol de localizare „peste nouă mări, peste nouă țări, peste nouă ape”, „locul unde și-a înțărcat dracul copiii”, „de nu m-oi duce unde a pus diavolu tămâia de să cutremură pământu ca piftia”, „mă duc în toată lumea / mă duc unde-a pus mutu iapa și surdu roata / unde-a pus nașu cățălu și finu purcelu”, „locul unde cocoșii nu cântă, nici câinii nu latră”. Mihaela Munteanu (2015: 208-209) numește acest tip de propoziții „structuri fixe” și afirmă că „specificitatea unei limbi se situează la nivel frazeologic, expresiile (cvasi)fixe «traducând» un anume mod de asumare a extraverbalului, de raportare la realitate, de cele mai multe ori aceste structuri fiind considerate intraductibile". Aceste construcții reflectă o fază pretoponimică, specifică numirii primare, arhaice. Au rol stilistic și sugerează existența unor ținuturi îndepărtate, vechi, a unor spații sacre dispărute, când omul sau „clanurile își primeau numele de la o adâncitură sau depresiune a terenului, determinate geografic, de la un anume furnicar" (Durkheim 2005: 77).

\section{Palierul morfosintactic}

Individualizarea numelor topice se realizează prin mijloace gramaticale cu ajutorul articolelor, a adjectivelor, a adverbelor, a prepozițiilor. Aceste categorii gramaticale au rolul de a fixa referentul. Articolul „lui” este folosit, de cele mai multe ori, cu forma populară „lu’” și însoțește și nume proprii feminine, deși este specific celor masculine. Cele mai multe toponime au determinanți și am identificat următoarele structuri: substantiv + substantiv în genitiv (Curtea Împăratului, Fântâna Sânzâienelor, Hotarele Scorpiei, Hotarele Zmeilor, Ostrovu Florilor, Țara Căpcăunilor), substantiv + substantiv în genitiv + substantiv în genitiv (Casa Zmeoaicei Pământului, Ostrovu Mărilor și al Oceanelor), substantiv + substantiv în genitiv + adjectiv (Casa Împăratului 
Verde, Curtea Împăratului Roșu), substantiv + adjectiv în nominativ (Câmpu Frumos, Fântâna Otrăvită, Pădurea Blestemată, Pădurea Roșie), substantiv + substantiv însoțit de prepoziție în acuzativ (Palat de Aur, Pădure cu Căldură, Pădure cu Ger, Pădurea de Fier, Muntele de Iagă), substantiv + adjectiv format prin conversiune (Meleagurile Aiestea, Tărâmu Celălalt - provenite din pronume, Tărâmu al Doilea - numeral cu valoare adjectivală), substantiv + adverb (Tărâmu de Jos, Tărâmu de Sus), substantiv + substantiv în acuzativ + adjectiv (Câmpul cu Iarbă Verde, Lacul cu Lapte Dulce). Din punct de vedere sintactic se poate observa că există localizări prin propoziții - „un castel dă să învârtea în jurul soarelui la fel ca într-un picior dă cocoș”, perifraze toponimice care elimină verbul (din explicit devine implicit), sintagme analitice, sintagme sintetice cu determinant în genitiv sau acuzativ. În basmele analizate există antroponime însoțite de articolul definit antepus (Castelul lui Crăcănea, Grădina lu’ Ileana Cosânzeana) care intră în structura numelor de locuri.

\section{Concluzii}

În demersul nostru, am urmărit să expunem câteva aspecte psiho- și sociolingvistice cu privire la numele de locuri din basme. Am evidențiat valoarea socială, istorică, dar și emoțională a toponimelor, deoarece acestea din urmă relevă atât relațiile interumane, cât și cele ale omului cu mediul geografic. Având în vedere transparența şi motivarea lor contextuală, topicele din basme păstrează legătura cu apelativul, tocmai pentru a putea fi decodificate facil. Am demonstrat că structura universului fabulos este bipolară, sacru vs. profan, fapt ce atrage după sine divizarea numelor de locuri în faste, bune și nefaste, rele, în funcție de circumstanță. Am văzut că atât lumea aceasta (casa, exteriorul casei, răscrucea, hotarele etc.), cât și lumea de pe „tărâmul celălalt” sunt impregnate de nume ale formelor de relief cu conotație negativă sau pozitivă, ale spațiilor umanizate (considerate sacre în gândirea arhaică și, totodată, în basme), ale locurilor tenebroase sau siderale, imitând construcția numelor din glosarul toponimic real. Astfel, am identificat în basme oiconime, oronime, hidronime, reale (au un referent în realitate), fictive (cu referent în universul fabulos și, uneori, și în lumea reală). Din punct de vedere semantic, am grupat toponimele în câmpuri toponimice, pornind de la teoria lui Coșeriu, care vizează câmpurile lexicale bazate pe opoziții echipolente, graduale, privative. La nivel lexical, am urmărit forma toponimelor (simple, derivate, compuse), cele mai multe fiind apelative in funcție toponimică. Palierul morfosintactic cuprinde părțile de vorbire prin care pot fi exprimate numele de locuri, în special, substantive în acuzativ, în genitiv, adjective, însoțite sau nu de prepoziții, adjective pronominale, adverbe. De asemenea, sunt întâlnite, la nivel sintactic, localizări prin propoziții, perifraze toponimice, sintagme analitice, sintagme sintetice cu determinant în genitiv, în nominativ. „Cât privește spațiul, aparent e simplu. E crucificat spre cele patru zări [...]. Între cer şi iad e purgatoriul catolic [...], iar prăpastia ne este predestinată” (Neț 2016: 168).

Toponimele din basme vizează spații miraculoase, unde muritorul de rând ajunge doar în situații liminale (Iadul, Raiul, Tărâmul Celălalt), domenii stâpânite de împărați 
și împărătese/ zâne (Împărăția Doamnei Chira Chiralina, Împărăția Zorilor) și, de cele mai multe ori, sunt atribuite unor ținuturi greu sau chiar imposibil de localizat, despre care au ştire doar iniţiații şi în care se găsesc obiecte cu puteri neobișnuite, locuiesc ființe ciudate, sunt ascunse fete de împărat răpite de zmei (Codrul Verde, Ostrovul Florilor, Palatul de Cleștar, Smârcurile Mărilor și ale Oceanelor).

\section{Bibliografie}

Ainiala, T., M. Saarelma, P. Sjöblom. 2016. Names in Focus. An Introduction to Finnish Onomastics. Translated by Leonard Pearl, Helsinki: Finnish Literature Society.

Bernea, E. 1997. Spațiu, timp și cauzalitate la poporul roman. Ediția a II-a, revizuită. București: Humanitas.

Blaga, L. 1985. Opere. Trilogia culturii, ediție îngrijită de Dorli Blaga, studiu introductiv de Al. Tănase. București: Editura Minerva.

Coșeriu, E. și H. Geckeler. 2016. Orientări in semantica structurală, traducere din limba engleză, notă preliminară. comentarii și postfaţă de Cristinel Munteanu. Iași: Editura Universității „Alexandru Ioan Cuza”.

David, J. 2011. Commemorative Place Names - Their Specificity and Problems. Names 59 (4): 214-228.

Dicționarul limbii române (DLR). 2010. București: Editura Academiei Române.

Durkheim, É. 2005. Formele elementare ale vieții religioase. Sistemul totemic in Australia. Traducere de Elisabeta Maria David. Iași: Editura Antet XX Press.

Eliade, M. 2000. Sacrul și profanul. Traducere din franceză de Brândușa Prelipceanu. Ediția a II-a. București: Humanitas.

Felecan, D. 2015. Sens lingvistic în „semnul estetic”. Buletin Ştiinţific XXIV: 47-61.

Felecan, D. 2017. Nume de botez - între sacru și profan. Abordare teoretică. În Proceedings of the Fourth International Conference on Onomastics "Name and Naming". Sacred and Profane in Onomastics, September 5-7, 2017, Baia Mare, O. Felecan (ed.), 19-34. Cluj-Napoca: Mega, Argonaut.

Felecan, D. și O. Felecan. 2016. Nicknames of Romanian Politicians after 1989. Philologica Jassyensia 2 (24): 191-207.

Felecan, O. 2017. Oikonymic Transformations in Romania in the Second Half of the Twentieth Century. Names 65 (2): 78-87.

Graur, A. 1972. Nume de locuri. București: Editura Științifică.

Ielenicz, M. 2004. Geomorfologie generală. București: Editura Universitară.

Iordan, I. 1963. Toponimie românească. București: Editura Academiei.

Jung, K. G. 2003. Opere complete. Arhetipurile și inconștientul colectiv. București: Editura Trei.

Loșonți, D. 2000. Toponime românești care descriu forme de relief. Cluj-Napoca: Editura Clusium.

Moldovanu, D. 1978. Chestionar toponimic și entopic general cu un glosar de entopice, onomasiologic. Iași: Institutul de lingvistică, istorie literară și folclor.

Moldovanu, D. 2010. Teoria câmpurilor toponimice (cu aplicație la câmpul hidronimului Moldova). Iaşi: Editura Universității „Alexandru Ioan Cuza”.

Moscal, D. 2013. Teoria câmpurilor lexicale. Cu aplicație la terminologia populară a formelor de relief pozitiv. Prefață de Maria Iliescu. Iași: Editura Universității „Alexandru Ioan Cuza”.

Munteanu Siserman, M. 2015. Nume și simțturi: corespondențe semantice în configurații denominative. Cluj-Napoca: Editura Mega, Argonaut. 
Neț, M. 2016. Capricii pe teme de basm. Cuvânt-înainte de Monica Pillat. București: Editura Eikon.

Nicolaisen, W.F.H. 2011. In the Beginning Was the Name. Selected Essays by Professor W.F.H. Nicolaisen. Shetland Litho: The Scottish Place-Name Society.

Olteanu, A. 2009. Reprezentări ale spațiului în credințele populare românești. București: Editura Paideia.

Şăineanu, L. 1997. Dicționar universal al limbei române, a cincea edițiune. Craiova: Editura „Scrisul Românesc”.

Van Langendonck, W. 2007. Theory and Typology of Proper Names. Berlin-New York. De Gruyter. Vaxelaire, J. L. 2005. Les noms propres une analyse lexicologique et historique. Paris: Editura Honoré Champion.

\section{Surse}

Bilțiu, P. (ed.). 1994. Făt-Frumos cel înțelept. O sută de basme, poveşti, legende, snoave şi povestiri din județul Maramureş. Baia Mare: Editura Gutinul.

Bilțiu, P. și M. Bilțiu. 2002. Basme, povești, povestiri, snoave și poezii populare din zona Codrului. Cluj-Napoca: Editura Dacia.

Creangă, I. 1990. Făt-Frumos, fiul iepei. Craiova: Editura Literatorul.

Creangă, I. 2002. Amintiri din copilărie. Poveşti. Povestiri. Bucureşti: Editura Vizual.

Creangă, I. 2008. Povești. Chișinău: Editura Pontos.

Delavrancea, B. Şt. 1989. Dl. Vucea. Bucureşti: Editura Ion Creangă.

Eminescu, M. 2009. Basme. București: Editura Tedit F2H.

Filimon, N. 1970. Basme şi nuvele. Bucureşti: Editura Ion Creangă.

Marian, S. Fl. 2010. Basmele românilor. București: Jurnalul Național.

Fochi, A. 1976. Datini și eresuri populare de la sfârșitul secolului al XIX-lea. București: Editura Minerva.

Ispirescu, P. (ed.). 2004. Cele mai frumoase basme. Bucureşti: Editura Cartea pentru toți. Lider. Ispirescu, P. (ed.). 2010. Basmele românilor. București: Editura Curtea Veche.

Oprișan, I. 2005. Basme fantastice românești. București: Editura Vestala.

Pamfile, T. 2002. Povestea lumii de demult după credințele poporului român. Pământul după credințele poporului român, sfârșitul lumii după credințele poporului român. București: Editura Paideia.

Slavici, I. 2010. Basmele românilor. București: Jurnalul Național.

Şerb, I. (ed.). 1982. Poveştile lui Făt-Frumos. Basme fantastice. Bucureşti: Editura Minerva. 